\title{
High nutrient supply and carbohydrate content reduce endophyte and alkaloid concentration
}

\author{
S. RASMUSSEN ${ }^{1}$, A.J. PARSONS ${ }^{1}$, Q. LIU ${ }^{1}$, H. XUE ${ }^{1}$ and J.A. NEWMAN ${ }^{2}$ \\ ${ }^{1}$ AgResearch Ltd., Private Bag 11008 Palmerston North, New Zealand \\ ${ }^{2}$ Department of Environmental Biology, University of Guelph, Ontario, Canada N1G2W1 \\ susanne.rasmussen@agresearch.co.nz
}

\begin{abstract}
Two controlled environment experiments were performed to test the effects of nitrogen, phosphorus and carbohydrates on endophyte (Neotyphodium lolii) and alkaloid concentrations in ryegrass (Lolium perenne). Three perennial ryegrass cultivars ('high sugar grasses' AberDove and AberDart; control Fennema) that differ in carbohydrate content were infected with three strains of $N$. lolii (common strain, CS; AR1; AR37). Infected and uninfected plants were grown under high $(9 \mathrm{mM})$ and low (2.25 mM) nitrogen (AberDove, Fennema; CS, AR1, AR37) or under high $\left(2 \mathrm{mM} \mathrm{KH} \mathrm{PO}_{4}\right)$ and low $\left(0.05 \mathrm{mM} \mathrm{KH}_{2} \mathrm{PO}_{4}\right)$ phosphorus (AberDart, Fennema; CS, AR1). Quantitative realtime Polymerase Chain Reaction (qPCR) was used to estimate endophyte concentrations in harvested leaf tissues. High $\mathrm{N}$ and P supply as well as high carbohydrate content of the host grass reduced endophyte concentrations. Alkaloid production was also reduced under both increased $\mathrm{N}$ supply and in the high sugar cultivar, and was linearly related to endophyte concentration (except ergovaline). The results stress the need for wider quantification of fungal endophytes in the grassland/ foliar endophyte context, and have implications for how introducing new cultivars, novel endophytes, or increasing nutrient inputs, affect the role of endophytes in grassland ecosystems.
\end{abstract}

Keywords: Neotyphodium lolii, foliar endophyte, Lolium perenne, perennial ryegrass, $\mathrm{qPCR}$, high sugar ryegrass, nitrogen, phosphate, carbohydrate, AR1, AR37, alkaloids

\section{Introduction}

An estimated $20-30 \%$ of all grass species host systemic fungal endophytes (Leuchtmann 1992), which grow in the intercellular spaces of primarily above ground organs and rely on nutrients assimilated by the plant (Clay 1990; Clay \& Schardl 2002). Endophytic fungi have been demonstrated to confer benefits to their grass hosts, notably through insect resistance/ repellence due to the production of alkaloids (see reviews by Malinowski \& Belesky 2000; Schardl et al. 2004). These associations have widely been regarded as mutualistic, but a meta-analysis of grass-endophyte literature suggests that the degree of mutual benefits is conditional on environmental factors like nutrient availability (Saikkonen et al. 2006).

The accumulation of alkaloids in plant tissues varies considerable in the field with season, weather and management, but there have been surprisingly few controlled studies of the effects of individual environmental components on alkaloid accumulation. In tall fescue, alkaloids were increased at elevated $\mathrm{N}$ availability, especially under moderate water stress (Arechevaleta et al. 1992), but in L. perenne Hunt et al. (2005) found N decreased alkaloid concentrations. Moderate phosphorus supply has been reported to increase ergot alkaloid concentration in tall fescue, but high $\mathrm{P}$ supply reduced its concentration (Malinowski et al. 1998). How carbohydrate content of the new "high sugar" grass cultivars effects alkaloid production and fungal concentration, to our knowledge, has been first reported by our group (Rasmussen et al. 2006).
One of the major difficulties encountered in previous studies has been assessing the concentration of the fungus, as it is necessary to address whether an environmental factor alters alkaloids by altering metabolism, or by altering the concentration of the fungus. In the present study we used qPCR to estimate fungal concentrations in infected plant tissues.

The $N$. lolii/ ryegrass association prevails in some of the most fertile, productive temperate grassland regions, typified by New Zealand. It is important to confirm whether recent trends for greatly increased use of $\mathrm{N}$ and $\mathrm{P}$ fertiliser, and the introduction of novel traits such as "high sugar" grass cultivars, will lead to sufficiently retained benefits of the association.

\section{Materials and Methods}

\section{Experiment 1 (nitrogen)}

The fundamental design of the experiment was a 3-way ANOVA comprising 2 grass cultivars (AberDove, Fennema), four endophyte treatments (CS, AR1, AR37 and 'Nil') and two levels of $\mathrm{N}$ supply ( $9 \mathrm{mM}, 2.25 \mathrm{mM})$. A total of 160 pots (10 replicates x 2 cultivars $x 4$ endophytes $x 2$ levels of nitrogen $x 2$ genotypes per pot) representing 320 genotypes were kept in 2 climate chambers in a random set-up. Material analysed represents leaf blades cut at $6 \mathrm{~cm}$ above ground. Real-time PCR and alkaloid analysis and statistical methods have been described in detail in Rasmussen et al. (2006).

\section{Experiment 2 (phosphorus)}

The fundamental design of the experiment was a 4-way ANOVA comprising 2 grass cultivars (AberDart, Fennema), 3 endophyte treatments (CS, AR1 and 'Nil'), 3 mycorrhizae treatments (Glomus mosseae, G. intraradices and 'Nil', analysis will be reported elsewhere) and $2 \mathrm{P}$ treatments ( $2 \mathrm{mM}$ and 0.05 $\left.\mathrm{mM} \mathrm{KH} \mathrm{PO}_{4}(\mathrm{~K}-\mathrm{Pi})\right)$. A total of 360 genotypes (10 replicates x 2 cultivars $x 3$ endophytes $x 2$ levels of phosphorus $\times 3$ mycorrhizae) were grown in pots (one plant per pot) containing pre-washed and steam autoclaved sand. The pots were randomly arranged in a climate chamber, fertilised by adding $30 \mathrm{ml} \mathrm{P}$ free Hoagland nutrient solution and watered at 2-day intervals. Plants were harvested after 12 weeks and separated into blades, pseudostems and roots, frozen in liquid nitrogen, freeze dried, and ground. Endophyte concentrations in pseudostems were estimated by quantitative real-time PCR (qPCR) of genomic DNA as described by Rasmussen et al. (2006). The data were log transformed and statistically analysed using GenStat v.9.

\section{Results and Discussion}

Endophyte concentration in plant tissue

The concentration of endophyte in the harvested plant material is expressed as the number of copies of each of two fungal specific genes (chitinase and NRPS-1, experiment 1; NRPS-1, experiment 2) per total (plant and fungus) genomic DNA. The main effects of sugar cultivar and nitrogen availability on the concentration of endophytes are shown in Fig. 1 a, b. Copy numbers of both 
Figure 1 Main effects of sugar cultivar (a) and $\mathrm{N}$ availability (b) on fungal concentrations expressed as gene copies ng-1 total genomic DNA. Black bars denote NRPS-1, white bars denote chitinase. Bars show the untransformed means and standard errors. There were no significant interactions (after Rasmussen et al. 2006).

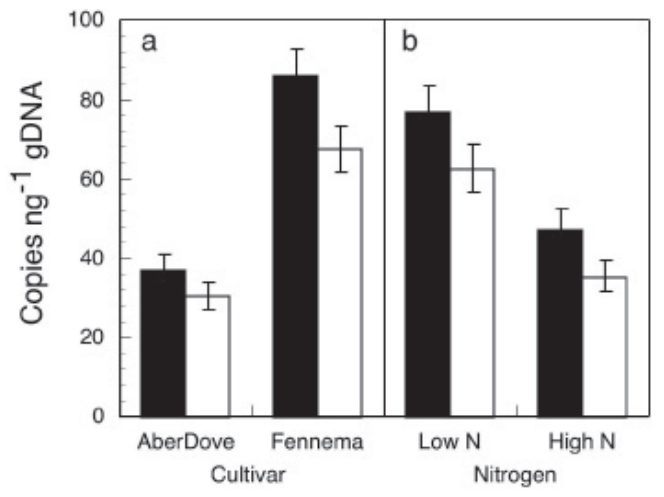

Main Effects of Treatment

endophyte genes, chitinase A and NRPS-1, were substantially reduced in AberDove-HSG compared to Fennema $(\mathrm{P}<0.001)$. Copy numbers of these two genes were also substantially reduced in plants supplied with high levels of nitrogen $(\mathrm{P}<0.001)$.

The main effects of sugar cultivar and phosphorus availability on the concentration of endophyte are shown in Fig. 2 a, b. Copy numbers of NRPS-1 were reduced in AberDart-HSG compared to Fennema $(\mathrm{P}<0.001)$ and were also substantially reduced in plants supplied with K-Pi (high $\mathrm{P}$ availability, $\mathrm{P}<0.001$ ).

Changes in alkaloid concentration could arise by 'dilution', if an environmental factor (such as $\mathrm{N}$ and $\mathrm{P}$ ) stimulated the growth of the grass plant more than it stimulated the growth of the fungus. The $50 \%$ (both at high $\mathrm{N}$ and $\mathrm{P}$ ) overall reduction in fungal concentration could be consistent with a 'dilution' effect, presuming a doubling of grass growth and no change in fungal growth. But 'dilution' is an unlikely explanation for the effects of the high sugar cultivar on fungal concentration, as differences in growth between these cultivars and Fennema are known to be small (Smith et al. 2002). However, in the case of both high nutrient supply ( $\mathrm{N}$ or $\mathrm{P}$ ) and sugar, changes in endophyte concentration could arise at an organ scale if these factors altered the proportion of new leaves and whole tillers that were successfully colonised.

\section{Alkaloid concentration in plant tissue}

The main effects of sugar cultivar and nitrogen on the concentration of alkaloids peramine and lolitrem B are shown in Fig. 3 a-d. The alkaloid peramine is produced only in plants infected with CS and AR1 endophytes. Peramine concentrations were significantly reduced in AberDove-HSG compared to Fennema $(\mathrm{P}<0.001)$ and under high nitrogen compared to low nitrogen $(\mathrm{P}<0.001)$. There were no significant interactions and no significant effect of endophyte strain (CS, AR1) on peramine.

Lolitrem B and ergovaline are produced only in plants infected with CS endophyte. AberDove had a lower concentration of lolitrem $\mathrm{B}$ than did Fennema $(\mathrm{P}<0.05)$ and nitrogen $(\mathrm{P}<0.01)$ reduced the concentrations of lolitrem $\mathrm{B}$ in $\mathrm{CS}$ infected ryegrasses. There was no significant interaction. There were no significant effects of cultivar, nitrogen or their interaction on the concentration of ergovaline (not shown as graph).
Figure 2 Main effects of sugar cultivar (a) and P availability (b) on fungal concentrations expressed as NRPS-1 gene copies $\mathrm{ng}^{-1}$ total genomic DNA. Bars show the untransformed means and standard errors. There were no significant interactions.

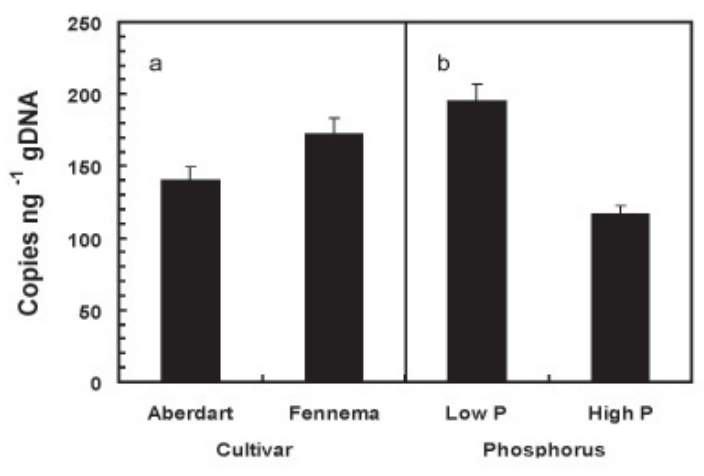

Janthitrems are produced only in plants infected with AR37. They followed the same general pattern as peramine and lolitrem $\mathrm{B}$, being significantly lower in AberDove-HSG than in Fennema $(\mathrm{P}<0.01)$ and in high $\mathrm{N}$ compared to low $\mathrm{N}(\mathrm{P}<0.001)$ (not shown as graph). There was no significant interaction.

Relationship between endophyte and alkaloid concentrations Factors such as cultivar (high sugar trait), or $\mathrm{N}$ supply, could alter the production of alkaloids either by altering the concentration of fungus per se, or by altering the rate of alkaloid production per unit endophyte. In Figures 1 and 3 there appears to be a similar trend in the way cultivar and $\mathrm{N}$ affect both endophyte and alkaloid concentrations. To examine this further, the two highly correlated estimates of endophyte concentration (copy numbers of NRPS1 and chitinase; Pearson correlation coefficient 0.905, $\mathrm{P}<0.001$, $\mathrm{R}^{2}=0.7752$ ) were condensed to a single principal component ( $1^{\text {st }}$ PC accounts for $95 \%$ of the total variance, both genes load positively and strongly onto $\mathrm{PC}-1$ ) and alkaloid concentrations were regressed against $\mathrm{PC} 1$. In all cases except ergovaline, the regression was highly significant (Fig. 4).

One study (Spiering et al. 2005) reported only a weak relationship between alkaloid and endophyte concentration (assessed using the GUS reporter gene) in a comparison between clonal populations of three plant genotypes selected for different endophyte content and distribution. In that study, much of the variation in endophyte content was between different tissues and tissue ages. In our present study, the variation in alkaloid and endophyte content comes from differences between genotypes within and between cultivars, and represents alkaloid and fungal concentrations in tissues of overall similar age. This may provide a more general representation of endophyte/ grass population responses to external environmental factors.

Not only does qPCR enable us to quantify endophyte content more widely, it also allows us to reconsider the scale of the contribution of the endophyte to metabolism and gene expression in the association. Based on the comparison of total amounts of DNA, it is often argued that the endophyte represents only 0.5 to $2 \%$ of the association; however, the haploid N. lolii genome is very small $(38 \mathrm{Mb})$ compared with the diploid ryegrass genome $\left(6.18 \times 10^{3} \mathrm{Mb}\right)$. Our results show that in leaf blades the ratios of fungal compartments (one gene copy $=$ one fungal compartment) 
Figure 3 Main effects of sugar cultivar $(a, c)$ and $\mathrm{N}$ availability (b, d) on peramine $(\mathrm{a}, \mathrm{b})$ and lolitrem $\mathrm{B}$ (c, d) concentrations. Black bars denote alkaloid concentrations in CS- and white bars denote alkaloid concentrations in AR1 infected $L$. perenne plants. Lolitrem B is only produced in CS infected plants. Plotted are the untransformed means and standard errors. All four pair wise comparisons on the Box-Cox transformed least squared means were significantly different; differences in peramine concentrations between the strains CS and AR1 in each treatment were not significant. There were no significant interactions (from Rasmussen et al. 2006).
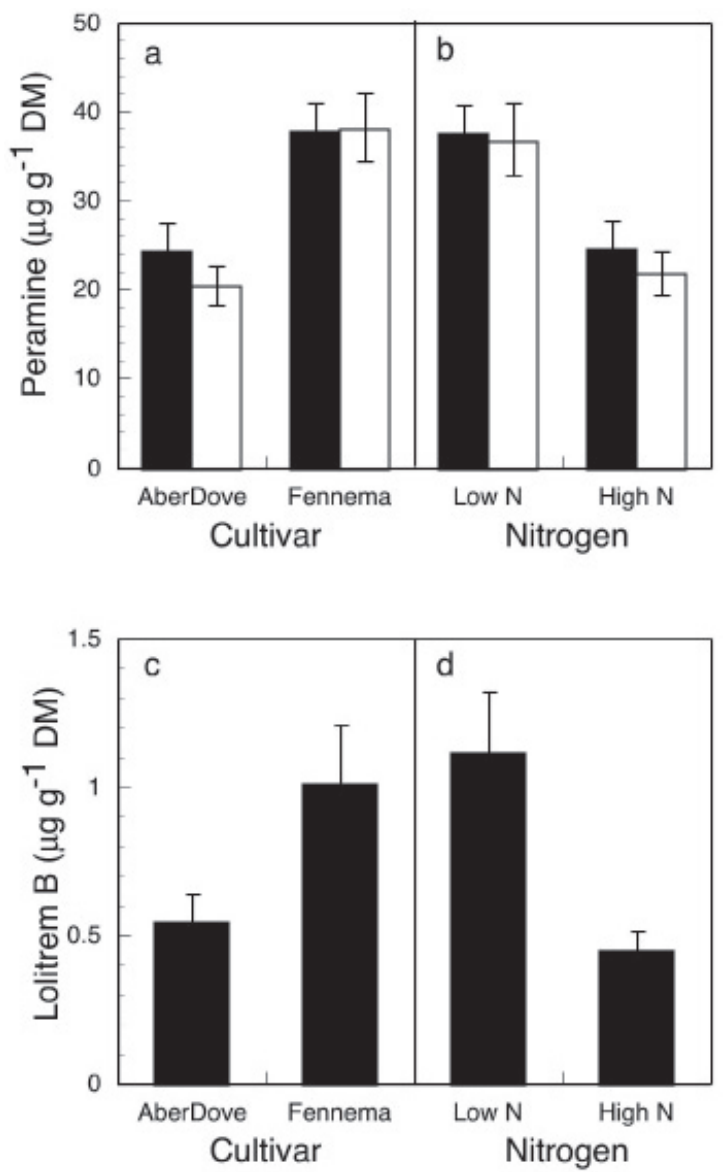

to plant cells may be as high as 1:2 to $1: 6$. The plant genome codes for 10000 to 60000 genes (Messing et al. 2004) but likewise the genome of the fungus Neurospora crassa $(40 \mathrm{Mb}$, similar to $N$. lolii), also codes for 11000 genes (Mannhaupt et al. 2003). The relatively high ratio of potentially expressed fungal genes suggests a more substantial contribution for the fungus in the association than has previously been perceived, and reemphasises the importance of a quantitative estimation of fungal concentrations if metabolic interactions between both organisms are to be interpreted.

\section{ACKNOWLEDGEMENTS}

We thank B. Tapper and E. Davies (AgResearch) for alkaloid
Figure 4 The relationship between untransformed alkaloid concentration ( $\left.\mu \mathrm{g} \mathrm{g}^{-1} \mathrm{DM}\right)$ and the fungal concentration represented by a $1^{\text {st }} \mathrm{PC}$ which is a positive linear combination of copy numbers $\mathrm{ng}^{-1}$ total gDNA of each of the two fungal specific genes: chitinase-A and NRPS-1. Below we give the overall F-ratio for each regression on the transformed concentrations and the equation for the untransformed relationship. Peramine $=3.05+8.57 x, R^{2}=$ $0.56, F_{1,76}=92.75, P<0.001$; Lolitrem $B=0.79+0.39 x, R^{2}=$ $0.53, F_{1,36}^{1,6}=52.19, \mathrm{P}<0.001 ;$ Ergovaline $=0.28+0.03 x, \mathrm{R}^{2}=$ $0.47, F_{1,36}=2.64, \mathrm{P}>0.05 ;$ Janthitrems $=0.78+0.37 \mathrm{x}, \mathrm{R}^{2}=$ $0.69, F_{1,38}=92.99, \mathrm{P}<0.001$ (from Rasmussen et al. 2006).
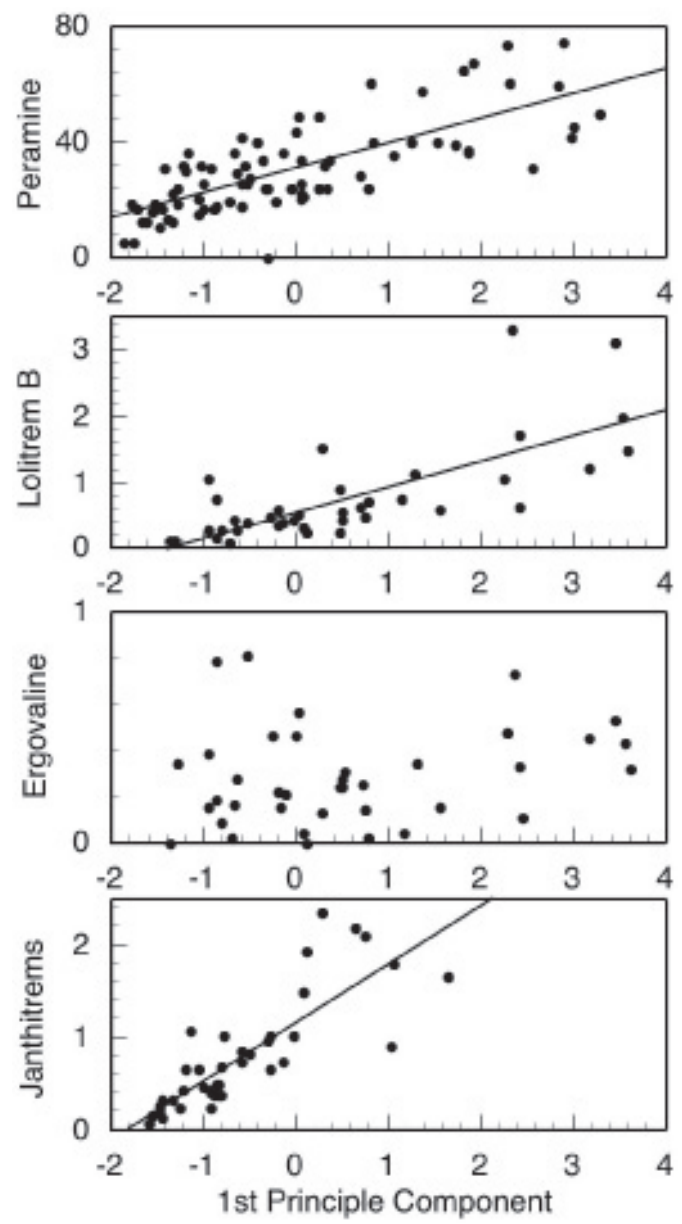

analysis. The work was funded by the Foundation of Research, Science and Technology (New Zealand).

\section{REFERENCES}

Arechevaleta, M.; Bacon, C.W.; Plattner, R.D.; Hoveland, C.S.; Radcliffe, D.E. 1992. Accumulation of ergopeptide alkaloids in symbiotic tall fescue grown under deficits of soil water and nitrogen fertiliser. Applied Environmental Microbiology 58: 857-861.

Clay, K. 1990. Fungal endophytes of grasses. Annual Review of Ecology and Systematics 21: 275-297.

Clay, K.; Schardl, C. 2002. Evolutionary origins and ecological consequences of endophyte symbiosis with grasses. American 
Naturalist 160: S99-S127.

Hunt, M.G.; Rasmussen, S.; Newton, P.C.D.; Parsons, A.J.; Newman, J.A. 2005. Near-term impacts of elevated $\mathrm{CO}_{2}$, nitrogen and fungal endophyte-infection on perennial ryegrass: growth, chemical composition and alkaloid production. Plant, Cell and Environment 28: 1345-1354.

Leuchtmann, A. 1992. Systematics, distribution, and host specificity of grass endophytes. Natural toxins 1: 150-162.

Malinowski, D.P.; Belesky, D.P.; Hill, N.S.; Baligar, V.C.; Fedders, J.M. 1998. Influence of phosphorus on the growth and ergot alkaloid content of Neotyphodium coenophialuminfected tall fescue (Festuca arundinacea Schreb.) Plant and Soil 198: 53-61.

Malinowski, D.P.; Belesky, D.P. 2000. Adaptations of endophyteinfected cool-season grasses to environmental stresses: mechanisms of drought and mineral stress tolerance. Crop Science 40: 923-940.

Mannhaupt, G.; Montrone, C.; Haase, D.; Mewes, H.W.; Aign, V.; Hoheisel, J.D.; Fartmann, B.; Nyakatura, G.; Kempken, F.; Maier, J.; Schulte, U. 2003. What's in the genome of a filamentous fungus? Analysis of the Neurospora genome sequence. Nucleic Acid Research 31: 1944-1954.

Messing, J.; Bharti, A.K.; Karlowski, W.M.; Gundlach, H.; Kim, H.R.; Yu, Y.; Wei, F.; Fuks, G.; Soderlund, C.A.; Mayer, K.F.X.; Wing, R.A. 2004. Sequence composition and genome organization of maize. Proceedings of the National Academy of Sciences of the United States of America. 101: 14349-14354.

Rasmussen, S.; Parsons, A.J.; Bassett, S.; Christensen, M.J.; Hume, D.E.; Johnson, L.J.; Johnson, R.D.; Simpson, W.R.; Stacke, C.; Voisey, C.R.; Xue, H.; Newman, J.A. 2006. High nitrogen supply and carbohydrate content reduce fungal endophyte and alkaloid concentration in Lolium perenne. New Phytologist (doi: 10.1111/j.1469-8137.2006.01960.x).

Saikkonen, K.; Lehtonen, P.; Helander, M.; Koricheva, J.; Faeth, S.H. 2006. Model systems in ecology: dissecting the endophyte-grass literature. Trends in Plant Science 11:428-433.

Schardl, C.; Leuchtmann, L.A.; Spiering, M.J. 2004. Symbioses of grasses with seedborne fungal endophytes. Annual Review of Plant Biology 55: 315-340.

Smith, K.F.; Culvenor, R.A.; Humphreys, M.O.; Simpson, R.J. 2002. Growth and carbon partitioning in perennial ryegrass (Lolium perenne) cultivars selected for high water-soluble carbohydrate concentrations. Journal of Agricultural Science 138: 375-385.

Spiering, M.J.; Lane, G.A.; Christensen, M.J.; Schmid, J. 2005. Distribution of the fungal endophyte Neotyphodium lolii is not a major determinant of the distribution of fungal alkaloids in Lolium perenne plants. Phytochemistry 66: 195-202. 